\title{
Effect of Aeration Rates on Removals of Organic Carbon and Nitrogen in Small Onsite Wastewater Treatment System (Johkasou)
}

\author{
Joni Aldilla Fajri ${ }^{1, *}$, Tomonari Fujisawa ${ }^{2}$, Yenni Trianda ${ }^{3}$, Yasushi Ishiguro $^{4}$, Guangyu $\mathrm{Cui}^{2}$, Fusheng $\mathrm{Li}^{4}$, and Toshiro \\ Yamada $^{5}$ \\ ${ }^{1}$ Faculty of Civil Engineering and Planning, Universitas Islam Indonesia, Kaliurang 55584, Indonesia \\ ${ }^{2}$ Graduate school of Engineering, Gifu University, Yanagido 501-1193, Japan \\ ${ }^{3}$ Department of Chemical Engineering of Natural Product, Polytechnic ATI Padang, Adinegoro Bungo Pasang 25586, Indonesia \\ ${ }^{4}$ River Basin Research Center, Gifu University, Yanagido 501-1193, Japan \\ ${ }^{5}$ Faculty of Engineering, Gifu University, Yanagido 501-1193, Japan
}

\begin{abstract}
Onsite application of oxygen supply in domestic wastewater system may be influenced by several factors that can inhibit the oxidation and nitrification processes. In this study, the influence of aeration rate on the Johkasou performance was focused using two Johkasou facilities serving up to five persons household. In the Johkasou A (JO-A) system, we increased the aeration rate from 30 to $63{\mathrm{~L} . \mathrm{min}^{-1}}^{-1}$ whereas, in the Johkasou B (JO-B), it was decreased from 59 to 34 L.min ${ }^{-1}$. Water and sludge samples were collected from the anaerobic-anoxic-oxic zones before and after adjustment of the aeration rate measured for organic matters and nitrogen parameters. Increasing the aeration rate in JO-A resulted in a high removal of organic matter $(82.5 \%)$ and nitrogen $(60.3 \%)$ compared to decreasing of aeration rate in $\mathrm{JO}-\mathrm{B}(52.0 \%$ and $33.0 \%$, respectively). Simultaneous nitrification and denitrification (SND) exhibited a maximum percentage when the aeration rate was increased compared to decreasing of aeration rate. These results indicate that application of a high aeration rate increases removal of organic matter and nitrogen and enhances ammonia transformation. It is therefore recommended to apply high aeration rates in Johkasou system.
\end{abstract}

\section{Introduction}

Small-scale onsite domestic wastewater treatment systems named Johkasou have been widely used in Japan's rural areas and are still developing the performance. Johkasou systems treat for both black and gray waters from household wastewater. The effluent of Johkasous is generally discharged into a local environmental receiving body, which the biochemical oxygen demand (BOD) and total nitrogen (TN) should be less than $20 \mathrm{~m} / \mathrm{L}$ [1]. Johkasou system is considered to be an effective means for wastewater treatment in rural areas, which are designed, located and maintained satisfactorily. Johkasou system consists of an anaerobic stage as a primary treatment unit (a primary settling tank) and a secondary anaerobic (anoxic) stage that both are equipped filter bed. And the aerobic (oxic) stage is a biological treatment unit typically like; activated sludge process, aerobic submerged biofilter, fluidized bed reactor, or biofilm filtration reactor. A disinfection chamber is also installed at end of the process to inactivate microorganisms and fecal indicator bacteria in the effluent before disposing to the environment.

During the last decade, biological nitrogen removal (BNR) has been promisingly method used both in domestic and industrial wastewater treatment [2]. A biological system is mostly eliminated the nitrogen compounds through combination processes of nitrification and denitrification. This system consists of two successive steps: 1) autotrophic nitrification in which $\mathrm{NH}_{4}{ }^{+} \mathrm{N}$ is oxidized to nitrite $\left(\mathrm{NO}_{2}{ }^{-} \mathrm{-N}\right)$ and then nitrate $\left(\mathrm{NO}_{3}^{-}-\mathrm{N}\right)$ under aerobic condition; and 2 ) heterotrophic denitrification in which $\mathrm{NO}_{3}{ }^{-}-\mathrm{N}$ is reduced to nitrogen gas $\left(\mathrm{N}_{2}\right)$ by heterotrophic denitrifiers under anoxic conditions with organic carbon as the electron donor [3].

Several studies reported the factors that inhibited nitrification-denitrification in biological system. These factors included higher free ammonia [4]-[6], hydraulic retention time (HRT) [7], [8], dissolve oxygen (DO) concentration and inhibitor [9]. However, the efficiency of biological nitrogen removal can be improved by maintaining and monitoring the ORP, $\mathrm{pH}$ and $\mathrm{DO}$ in the nitrification-denitrification process [10]. Peng et al.[11] conducted the real-time aeration control using $\mathrm{pH}$ and DO in sequence batch reactor, and found that the end of nitrification could be identified by the binding the point in $\mathrm{pH}$ and increased in $\mathrm{DO}$ profile.

Recently, studies of BNR process mainly used DO as a limiting factor to achieve the nitrification and

\footnotetext{
Corresponding author: joni.af@uii.ac.id
} 
denitrification [7], [11], [12]. Dissolved oxygen is also economically feasible control the parameters particularly at low concentration that can save the aeration consumption, while in some cases the efficiency of BNR can be achieved at high DO concentration. Therefore, there is no definitive explanation regarding an appropriate DO concentration to achieve complete nitrification. Guo et al. [7] conducted the partial nitrification by comparing the high and low DO concentration ( 2.5 and $0.5 \mathrm{mg} / \mathrm{L}$, respectively) on longterm aeration time. The complete nitrification was reached at both conditions, which corresponded increase nitrite concentration and kept constant or nearly negligible the nitrate concentration. Under limited oxygen condition, Jianglong and Ning [13] reported that significantly higher ammonia oxidation rate was reached when increased the DO concentration from 0.5 to 1.5 $\mathrm{mg} / \mathrm{L}$. Another study found that temporal nitrite accumulation was obtained at medium of DO at 1.7 $\mathrm{mg} / \mathrm{L}$, however, the excess of DO concentration had no influence on nitrite accumulation, while at low DO concentration decreased the nitrite accumulation and ammonia consumption [14].

The successful of DO concentration in BNR process can also be measured by simultaneous nitrification and denitrification. The efficiency of SND mainly occurs as consequence of DO concentration gradients within microbial flocs of biofilms due to diffusional limitation. This indicates the appropriate application of DO for degrading organic matter and producing less sludge. In batch scale reactor, many researchers pointed that high efficiency of SND was achieved during low DO concentration [7], [15], [16], which remained organic compounds used by denitrifying bacteria. Contrary, Zhu et al. [8] noted that the SND could be obtained even at high DO concentration under variances of alkalinity concentration.

The studies on nutrient and organic removal using biological system were mostly conducted in a batch reactor that is easy to control and less complexity in the system. The application of BNR in the real system or insitu study faces many factors such as air supply clogging, low oxygen availability and out of usage of a blower. These factors may reduce the aeration rate and then decrease organic and nutrient removal in wastewater treatment system. It will result in poor effluent quality discharged to the local water and can deteriorate downstream water environment. Moreover, little research was conducted in Johkasou system to study the effect of aeration rate and there is no authentic regulation on setting the aeration rate by third parties. Therefore, the objective of this study was to know the effect of aeration rate in the biological process involved in the removal of organic and nitrogen in Johkasou system during onsite research and to find the appropriate aeration rate that can apply in this system.

\section{Material and methods}

\subsection{Description of Johkasou system}

We studied the effect of aeration rate in two Johkasou facilities. The experiments were carried out in two installed Johkasou facilities (CE-5, Fuji clean, Japan) used up to five family members (Fig. 1). Johkasou system is a household-size unit with a capacity of $1-2 \mathrm{~m}^{3}$ per day. It composes of a primary treatment unit consisting of an anaerobic settling tank as sludge store and a down-flow anaerobic filter packed media as an anoxic process, the aerobic reactor coupled with a fixed filtration bed, and then a final settling tank and a disinfection chamber [1]. The filter packed media in the anaerobic zone and the fixed filtration bed in the oxic zone is made of polystyrene material. A blower was utilized to provide the air for sufficient gas-liquid mixing in aerobic treatment. Adjustable opening valves in the aeration tank were used to control the air supply and recirculate the settled sludge from the bottom of the aeration tank to the anaerobic settling tank. The maintenance of the system is generally conducted once in four months, while the cleaning and sludge dragged are scheduled once a year.

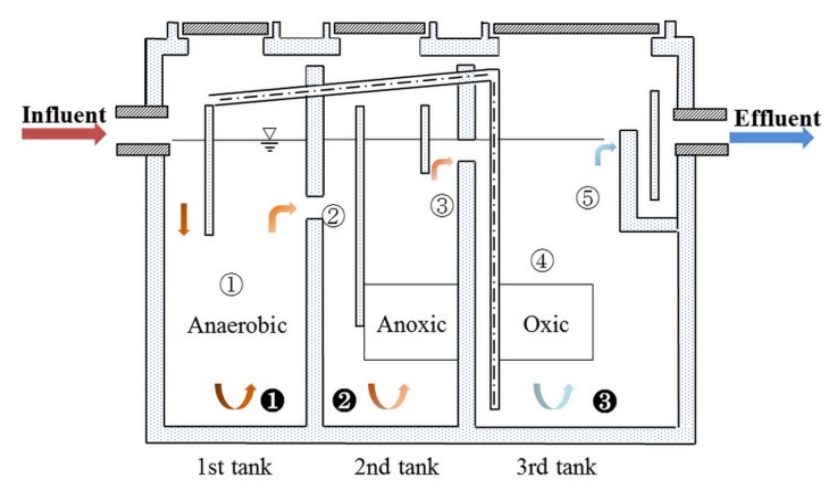

Fig. 1. Structure of Johkasou used in the study and sampling points. Open numbers from 1 to 5 are water sampling in each zone; influent in the anaerobic, effluents of anaerobic and anoxic, oxic and settling tank, respectively. Bold numbers from 1 to 3 indicate sludge samplings in each zone.

\subsection{Experimental operation and sampling}

The two Johkasou systems, Johkasou A (JO-A) and Johkasou B (JO-B), were operated under different aeration supplies. The JO-A was utilized at high aeration rate, which an initial rate was $30 \mathrm{~L} / \mathrm{min}$ started from October 15th, 2015. After two weeks of operation and collecting sample prior adjustment, the aeration rate was increased to $63 \mathrm{~L} / \mathrm{min}$ and then maintained till end of the operation (December 17, 2015). We assumed that the steady state of the system in JO-A was achieved within two weeks after increasing aeration and the sample collections were started on this date and continued for bi-weekly sampling. The total operation time of JO-A was 71 days and mean influent loading was $0.58 \mathrm{~m}^{3} / \mathrm{d}$.

The JO-B was operated as low aeration rate with an initial rate of $59 \mathrm{~L} / \mathrm{min}$ started from September $1^{\text {st }}, 2015$. After ten days operation and collecting samples prior 
Table 1. Initial influent characteristics in both Johkasou.

\begin{tabular}{|c|c|c|c|c|c|c|c|c|}
\hline & $\begin{array}{c}\text { Influent flow } \\
\text { rate } \\
\left(\mathrm{m}^{3} / \mathrm{d}\right)\end{array}$ & $\begin{array}{c}\mathrm{A}_{r}{ }^{\mathrm{a}} \text { before } \\
\text { adjustment } \\
(\mathrm{L} / \mathrm{min})\end{array}$ & $\begin{array}{c}\mathrm{A}_{r} \text { After } \\
\text { adjustment } \\
(\mathrm{L} / \mathrm{min})\end{array}$ & $\begin{array}{l}\text { BOD } \\
(\mathrm{mg} / \mathrm{L})\end{array}$ & $\begin{array}{l}\text { DOC } \\
(\mathrm{mg} / \mathrm{L})\end{array}$ & $\begin{array}{c}\mathrm{TN} \\
(\mathrm{mg} / \mathrm{L}) \\
\end{array}$ & $\begin{array}{c}\mathrm{TP} \\
(\mathrm{mg} / \mathrm{L})\end{array}$ & $\begin{array}{l}\mathrm{NH}_{4}{ }^{+}-\mathrm{N} \\
(\mathrm{mg} / \mathrm{L})\end{array}$ \\
\hline Incr & $0.52 \pm 0.08$ & 30 & 63 & $258.0 \pm 21.7$ & $65.4 \pm 24.0$ & $50.2 \pm 4.1$ & $5.9 \pm 0.4$ & $38.4 \pm 2.9$ \\
\hline Decrease aeration (JO-B) & $0.38 \pm 0.06$ & 59 & 34 & $225.0 \pm 54.5$ & $40.0 \pm 12.4$ & $51.8 \pm 8.3$ & $5.0 \pm 0.9$ & $38.0 \pm 8.8$ \\
\hline
\end{tabular}

${ }^{\mathrm{a}} \mathrm{A}_{r}$ indicates aeration rate

Values are mean \pm standard deviation.

adjustment, the aeration rate was decreased to $34 \mathrm{~L} / \mathrm{min}$ and maintained up to end of the operation (November $\left.5^{\text {th }}, 2015\right)$. We assumed that the steady state of the system in JO-B was achieved within a month operation after decreasing the aeration and then the samples were collected and continued for bi-weekly samplings here after. The total operation time of JO-B was 63 days and the mean influent loading was $0.38 \mathrm{~m}^{3} / \mathrm{d}$.

\subsection{Wastewater and sludge characteristics}

Each of Johkasou system received continuous influent (black and gray waters) from single house. The influent characteristics of both Johkasou systems were described in Table 1. During the operation, there was no sludge recycled either before or after adjustment of aeration. The mixed-liquor suspended solid (MLSS) and mixed-liquor volatile suspended solid (MLVSS) of sludge were measured and the result is displayed in Table 2.

\subsection{Sample collection and analytical methods}

We collected water samples from several sampling points in order to study the differences of effluent quality for each stage before and after adjustment of aeration rate. Water samples were obtained from the influent of anaerobic zone, effluents from anaerobic, anoxic and oxic zone, and settling zone. From each sampling points, water samples were taken once before adjustment as initial condition and bi-weekly after it. And, we also grabbed sludge samples at the bottom of each zone. The samples of water and sludge phases were transferred into one litter polystyrene plastic bottle and stored in a cooling box before transporting to the laboratory. Then, the samples were analyzed soon on the same day for organic matter and nutrients.

We measured the physico-chemical parameters to identify the basic effluent quality at each zone. The physical parameters such as oxidation reduction potential (ORP), $\mathrm{pH}, \mathrm{DO}$, and water temperature $\left(\mathrm{T}_{\mathrm{w}}\right)$ were measured onsite once a week. The measurements of ORP, pH, DO, and Tw were done using the corresponding portable probe meters (DKK-TOA, Tokyo, Japan). The organic matter and nutrients constituents including biochemical oxygen demand for 5 days at $25^{\circ} \mathrm{C}(\mathrm{BOD})$, dissolved organic carbon (DOC), turbidity, suspended solid (SS), volatile suspended solid (VSS), total nitrogen (TN), total phosphorous (TP), ammonia-N
$\left(\mathrm{NH}_{4}{ }^{-}-\mathrm{N}\right)$, nitrite- $\mathrm{N}\left(\mathrm{NO}_{2}^{-}-\mathrm{N}\right)$ and nitrate- $\mathrm{N}\left(\mathrm{NO}_{3}{ }^{-}-\mathrm{N}\right)$ in the water samples; and MLSS, MLVSS and sludge volume index (SVI) in the sludge samples were analyzed according to standard methods [17].

\subsection{Statistical analyses}

Statistical analysis was calculated to find the differences among means and influence of aeration rates on the wastewater quality variables. One-way ANOVA with Post-Hoc Honest tests, Tukey HSD was used to obtain the variance data between the Johkasou systems.

\section{Results and discussion}

\subsection{Physical parameters}

The mean values of physical parameters at each zone are displayed in Table 2. The ORP values showed the difference before and after adjustment of aeration rate for both JO-A and JO-B. At anoxic and oxic zones, the mean of ORP ranged from -110.0 to $-250.5 \mathrm{mV}$ before adjustment and from -24.1 to $93.4 \mathrm{mV}$ after adjustment for JO-A, and from 102 to $116 \mathrm{mV}$ before adjustment and from -101.4 to $49.5 \mathrm{mV}$ after adjustment for JO-B. These results implied that the ORP increased by increasing oxygen supply and dropped when the oxygen supply was shortened. The $\mathrm{pH}$ in both Johkasous (ranged from 6.7 to 7) was sufficient for nitrification ( $\mathrm{pH}$ $>6.5$ ) and demonstrated a slight drop during nitrifying aeration phase as according to Canziani et al. [18]. The water temperature was similar before and after adjustment of aeration rate for both JO-A and JO-B, which indicated that seasonal effect was not the main factor reflecting the water temperature.

Difference concentrations in DO were recognized between before and after adjustment of aeration rate. In the anaerobic stage, concentration of DO was recorded at zero and ORP was lower than $-250 \mathrm{mV}$ for both Johkasous. In the anoxic zone, significance in DO concentrations was showed after adjustment of aeration rate. It increased from 0.2 to $2.7 \mathrm{mg} / \mathrm{L}$ after increasing DO for JO-A and decreased from 5.1 to $0.9 \mathrm{mg} / \mathrm{L}$ after decreasing DO for JO-B, which indicated that the limited oxygen supply could be transferred from the oxic zone through upflow system. High DO concentrations in the anoxic zone might be caused the excess oxygen supply in the oxic zone whereas the mean values of ORP were - 
Table 2. Parameter indexes measured in this study.

\begin{tabular}{|c|c|c|c|c|c|c|c|c|c|c|}
\hline & \multicolumn{5}{|c|}{ Before adjustment } & \multicolumn{5}{|c|}{ After adjustment } \\
\hline & Inffluent & $\begin{array}{c}\text { 1st Stage } \\
\text { Anaerobic }\end{array}$ & $\begin{array}{l}\text { 2nd Stage } \\
\text { Anaerobic }\end{array}$ & Aerobic & Settling & Inffluent & $\begin{array}{c}\text { 1st Stage } \\
\text { Anaerobic }\end{array}$ & $\begin{array}{l}\text { 2nd Stage } \\
\text { Anaerobic }\end{array}$ & Aerobic & Settling \\
\hline \multicolumn{11}{|c|}{ Increasing aeration (JO-A) } \\
\hline ORP (mV) & $-250.5(2)$ & - & $-236(2)$ & $-110.5(2)$ & $-250.5(2)$ & $-249.1 \pm 24.0(8)$ & - & $-24.1 \pm 50.3(8)$ & $93.4 \pm 25.1(8)$ & $44.3 \pm 63.6(8)$ \\
\hline $\mathrm{pH}$ & $6.1(2)$ & $6.2(2)$ & $7.3(2)$ & $7.3(2)$ & $7.2(2)$ & $6.2 \pm 0.1(8)$ & $6.2 \pm 0.1(8)$ & $6.7 \pm 0.2(8)$ & $6.7 \pm 0.3(8)$ & $6.6 \pm 0.2(8)$ \\
\hline $\mathrm{DO}(\mathrm{mg} / \mathrm{L})$ & $0(2)$ & $0(2)$ & $0.2(2)$ & $1(2)$ & $0(2)$ & $0 \pm 0.0(8)$ & $0 \pm 0.0(8)$ & $2.7 \pm 0.9(8)$ & $5 \pm 0.9(8)$ & $1 \pm 0.7(8)$ \\
\hline $\operatorname{Tw}\left({ }^{\circ} \mathrm{C}\right)$ & $24.6(2)$ & - & $24.6(2)$ & - & $24.3(2)$ & $24.0 \pm 1.8(8)$ & - & $21.3 \pm 1.8(8)$ & - & $21.0 \pm 2.0(8)$ \\
\hline Turbidity (NTU) & $55(1)$ & $80(1)$ & $23(1)$ & $23(1)$ & $21(1)$ & $113.3 \pm 15.1(4)$ & $117.8 \pm 166.7(4)$ & $9.1 \pm 2.7(4)$ & $4.5 \pm 0.3(4)$ & $3.9 \pm 1.0(4)$ \\
\hline TSS (mg/L) & $63(1)$ & $97(1)$ & $12(1)$ & $13(1)$ & $14(1)$ & $67.0 \pm 12.5(4)$ & $78.5 \pm 21.3(4)$ & $12.6 \pm 4.6(4)$ & $9.6 \pm 3.1(4)$ & $5.1 \pm 34(4)$ \\
\hline VSS (mg/L) & $57(1)$ & $95(1)$ & $9.4(1)$ & $11(1)$ & $13(1)$ & $58.8 \pm 12.8(4)$ & $70.0 \pm 19.1(4)$ & $11.5 \pm 4.7(4)$ & $8.2 \pm 2.4(4)$ & $4.1 \pm 2.2(4)$ \\
\hline MLSS (mg/L) & 16,435 & - & 11,173 & 4,028 & 4,000 & $16,690.0 \pm 7322.4$ & - & $9,745.6 \pm 725.5$ & $4,337.8 \pm 408.3$ & $5,275.6 \pm 2,386.4$ \\
\hline MLVSS (mg/L) & 16,310 & - & 10,283 & 3,970 & 3,928 & $15,910.0 \pm 7087.4$ & - & $8,966.3 \pm 831.0$ & $4,174.4 \pm 459.2$ & $4,960.0 \pm 2,066.1$ \\
\hline \multicolumn{11}{|c|}{ Deacreasing aeration (JO-B) } \\
\hline ORP (mV) & $-343(2)$ & - & $104.5(2)$ & $116(2)$ & $102(2)$ & $-265.0 \pm 104.3(8)$ & - & $-101.4 \pm 75.5(8)$ & $49.5 \pm 40.1(8)$ & $-97.4 \pm 147.8(8)$ \\
\hline $\mathrm{pH}$ & $6.7(2)$ & $6.7(2)$ & $6.5(2)$ & $6.4(2)$ & $6.5(2)$ & $6.3 \pm 0.3(8)$ & $6.5 \pm 0.2(8)$ & $7.1 \pm 0.2(8)$ & $7.1 \pm 0.2(8)$ & $7.0 \pm 0.2(8)$ \\
\hline DO $(\mathrm{mg} / \mathrm{L})$ & $0(2)$ & $0(2)$ & $5.1(2)$ & $7(2)$ & $2.8(2)$ & $0.0 \pm 0.0(8)$ & $0.0 \pm 0.0(8)$ & $0.9 \pm 0.8(8)$ & $2.3 \pm 0.8(8)$ & $0.1 \pm 0.2(8)$ \\
\hline $\operatorname{Tw}\left({ }^{\circ} \mathrm{C}\right)$ & $26(2)$ & - & $26.0(2)$ & - & $26.0(2)$ & $23.2 \pm 1.6(8)$ & - & $23.3 \pm 1.9(8)$ & - & $22.8 \pm 1.6(8)$ \\
\hline Turbidity (NTU) & $34(1)$ & $35(1)$ & $6.9(1)$ & $6(1)$ & $6.9(1)$ & $63.7 \pm 18.9(3)$ & $66.7 \pm 14.6(3)$ & $13.2 \pm 6.0(3)$ & $7.2 \pm 0.6(3)$ & $5.7 \pm 1.2(3)$ \\
\hline TSS (mg/L) & $40(1)$ & $18(1)$ & $9.4(1)$ & $12(1)$ & $9(1)$ & $60.3 \pm 23.4$ & $70.0 \pm 27.9(3)$ & $21.0 \pm 1.0(3)$ & $19.0 \pm 3.6(3)$ & $13.0 \pm 2.0(3)$ \\
\hline VSS (mg/L) & $36(1)$ & $16(1)$ & $7.5(1)$ & $10(1)$ & $8.5(1)$ & $55.7 \pm 25.7$ & $63.0 \pm 21.7(3)$ & $18.3 \pm 0.6(3)$ & $15.7 \pm 3.5(3)$ & $10.8 \pm 2.9(3)$ \\
\hline MLSS (mg/L) & 20,740 & - & 10,130 & 5,750 & 2,685 & $14,467.5 \pm 5203.6$ & - & $8,266.3 \pm 2,198.1$ & $5,697.1 \pm 715.5$ & $3,603.8 \pm 2,174.5$ \\
\hline MLVSS (mg/L) & 19,970 & - & 9,705 & 5,573 & 2,400 & $13,442.5 \pm 5568.9$ & - & $7,595.0 \pm 2,186.7$ & $5,295.0 \pm 881.9$ & $3,280.0 \pm 2,153.4$ \\
\hline
\end{tabular}

Values after adjustment are mean \pm standard deviation and parentheses indicate number of samples.

$24.5 \mathrm{mV}$ and $-101.4 \mathrm{mV}$ for JO-A and JO-B respectively, which these zones indicated as the facultative aerobic state. In the oxic zone, the mean concentrations of DO were 5 and $2.3 \mathrm{mg} / \mathrm{L}$ for $\mathrm{JO}-\mathrm{A}$ and $\mathrm{JO}-\mathrm{B}$, respectively, and the mean ORP was +49.5 and $+93.4 \mathrm{mV}$ for JO-A and JO-B, respectively, which indicated both Johkasou were well supplied with oxygen (Table 2).

\subsection{Suspended solid and biomass properties}

The concentrations of TSS and VSS in water samples are shown in Table. 2. Concentration of TSS and VSS before adjustment for JO-A and JO-B showed similar values in the anoxic and oxic zones. After adjustment, however, concentrations of TSS and VSS were nearly two times lower in the JO-A then in the JOB. The ratio of VSS/TSS in JO-A turned into less than JO-B with a value from 85.0 to $87.5 \%$ and 82.7 to $91 \%$, respectively. These results indicated that increasing of aeration rate could increase conversion of ammonia and other soluble organic into biomass.

Initial concentrations of MLSS and MLVSS in the JO-A and JO-B were operated in different sludge concentrations; whereas, in the oxic zone, concentrations of MLSS and MLVSS pointed a slightly lower at high aeration rate rather than low aeration rate (Table 2). These results were found at same circumstance after adjustment of aeration rates. This indicated that high aeration rate could be an important factor to degrade organic carbon and increase the number of biomass. The ratios of MLVSS/MLSS for the whole operating condition were $91.6 \%$ and $94.4 \%$ respectively in $\mathrm{JO}-\mathrm{A}$ and JO-B, represented a high proportion of biomass in the sludge.

\subsection{Removal of organic carbon and nitrogen by increasing aeration rate in JO-A}

Concentrations of organic compound and nutrient in JO-A before and after adjustment of aeration rate are shown in Fig. 2. The removals of DOC and BOD were used as representative of a part of total organic matter and biodegradable organic matter, respectively. Removal percentages of BOD and DOC after adjustment of aeration rate were not significantly different.

Increasing DO concentration showed an improvement of organic carbon removal in the Johkasou system. When the aeration rate increased from 30 to 63 $\mathrm{L} / \mathrm{min}$, the DO concentration lifted from 0.19 to 2.7 $\mathrm{mg} / \mathrm{L}$ and from 1 to $5 \mathrm{mg} / \mathrm{L}$ in the anoxic and the oxic zones, respectively. Before adjustment, at low aeration rate $(30 \mathrm{~L} / \mathrm{min})$, total removals of BOD and COD were $81.7 \%$ and $40 \%$, respectively. However, total removals of organic carbon increased sharply onto $98.1 \%$ and $91.1 \%$ for BOD and DOC, respectively, when the aeration rate was increased into $63 \mathrm{~L} / \mathrm{min}$. Proportions of organic carbon removal were detected mainly occur in the anoxic zone. This indicated that high DO improved organic carbon oxidation in the anoxic zone and remained organic carbon was utilized by autotrophic bacteria in nitrification process in the oxic zone. Effect of increasing DO on improvement of organic removal was also reported by several studies [16], [19]-[22].

Concentrations of $\mathrm{TN}$ and $\mathrm{NH}_{4}^{+}-\mathrm{N}$ in JO-A before and after adjustment aeration rate are displayed in the Fig. 2b. Before adjustment of aeration rate, at low DO of $0.19 \mathrm{~L} / \mathrm{min}$, removals of $\mathrm{TN}$ and $\mathrm{NH}_{4}{ }^{+}-\mathrm{N}$ could not be found in both the anoxic and the oxic zones. It reveals that the operation of Johkasou at low DO is inappropriate for nitrifier bacteria to produce nitrite and nitrate from oxidized ammonia as shown in Fig. 4. 

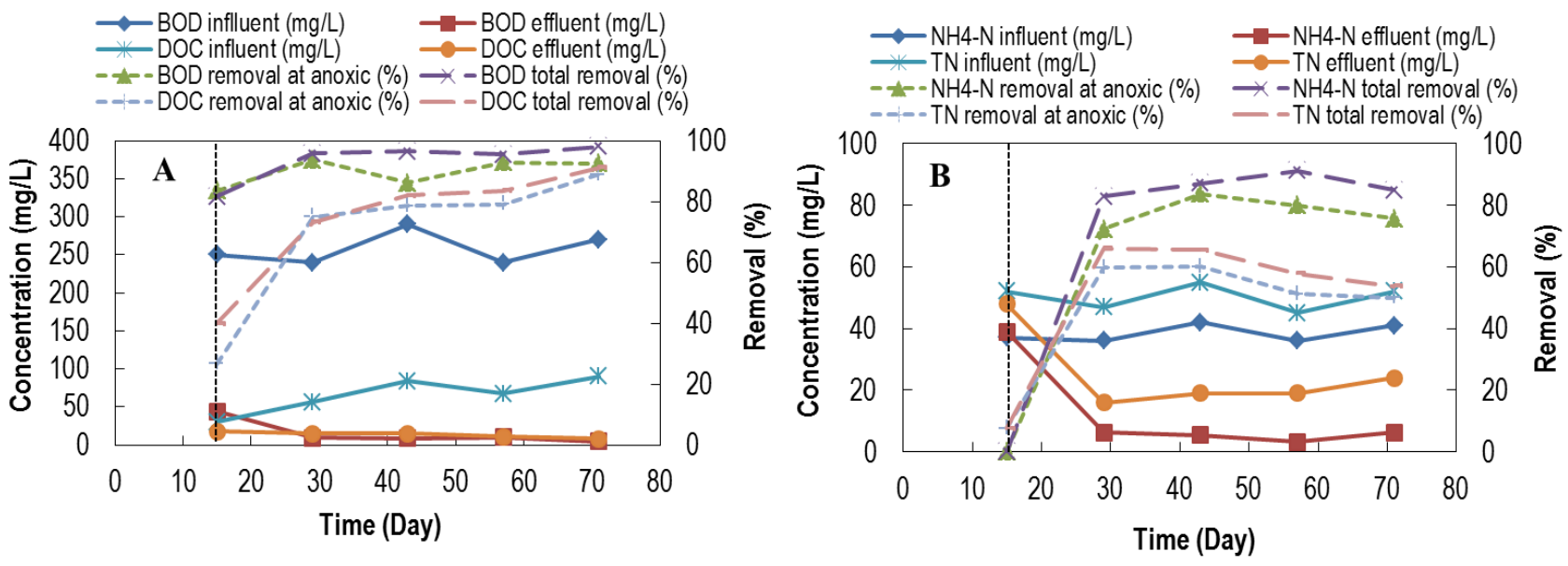

Fig. 2. Concentrations of a) organic carbon and b) nitrogen in JO-A during operation. Concentrations at dash line indicate the operation before adjustment with an aeration rate of $30 \mathrm{~L} / \mathrm{min}$ and then, the aeration rate was increased to $63 \mathrm{~L} / \mathrm{min}$ (after adjustment).
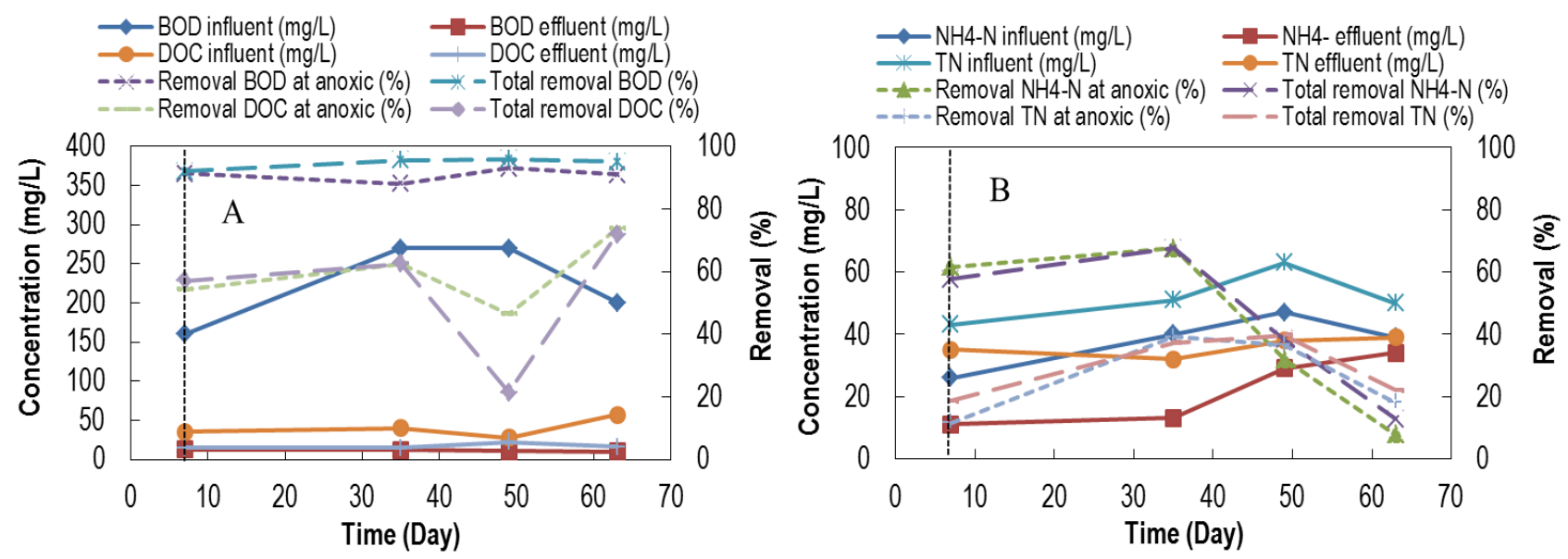

Fig. 3. Concentrations of organic matter and nitrogen in JO-B during operations. Concentrations at dash line indicate the operation condition before adjustment with an aeration rate of $59 \mathrm{~L} / \mathrm{min}$ and then, the aeration rate was decreased to $34 \mathrm{~L} / \mathrm{min}$ (after adjustment).

Conversely, $\mathrm{TN}$ and $\mathrm{NH}_{4}^{+}-\mathrm{N}$ removals increased sharply when DO was increased to be $2.7 \mathrm{mg} / \mathrm{L}$ in the anoxic zone and the removals of these compound ranged from 50 to $60 \%$ and from 72 to $83 \%$, respectively. The excess DO in the oxic zone could only remove the TN up to $65 \%$ while $\mathrm{NH}_{4}{ }^{+}-\mathrm{N}$ removal reached to $91 \%$, respectively. These results indicate that high DO is an appropriate condition for Johkasou system to oxidize TN and transform the ammonia into $\mathrm{NO}_{2}{ }^{-}-\mathrm{N}$ and $\mathrm{NO}_{3}{ }^{+}-\mathrm{N}$ forms.

\subsection{Removal of organic carbon and nitrogen by decreasing aeration rate in JO-B}

Concentrations of organic carbon and nitrogen during low aeration condition in the JO-B system are displayed in Fig. 3. The removals of BOD and DOC were statistically not difference between before and after adjustment. Before adjustment with a high aeration rate
(59 L/min), DO concentration in the anoxic and oxic zones was in very rich condition on the level of $6.1 \mathrm{mg} / \mathrm{L}$ and $7.5 \mathrm{mg} / \mathrm{L}$, respectively. At this condition, BOD and DOC removal could be obtained with mean percentages of $95.5 \%$ and $71.9 \%$, respectively, and most removals of these organic carbon occurred in the anoxic zone $(91.9 \%$ and $62.5 \%$, respectively). The removal of $\mathrm{NH}_{4}{ }^{+}-\mathrm{N}$ was in moderate level around $57 \%$, however, TN removal could not be obtained. These results suggested that excess DO concentration in the oxic zone changed the state of anoxic condition into rich DO that was not sufficient for reducing $\mathrm{TN}$ and ammonia.

Contradictory results were obtained when the aeration rate was decreased. When aeration rate decreased from 59 to $34 \mathrm{~L} / \mathrm{min}$, DO concentration dropped from 5.1 to $0.9 \mathrm{mg} / \mathrm{L}$ and from 7 to $2.3 \mathrm{mg} / \mathrm{L}$ both in anoxic and oxic zones, respectively. Decreasing DO concentration leads to slightly declined DOC removal from $73.7 \%$ to $71.9 \%$ and sharp declined of 
$\mathrm{NH}_{4}{ }^{+}-\mathrm{N}$ from 57.7 to $12.8 \%$. However, total removal of TN showed increased trend to $22 \%$. This condition suggests that the organic consumption was not properly achieved during nitrification in which nitrifier growth much slower than heterotrophic bacteria, and caused competition of oxygen consumption between both groups of organisms.

These results indicate that high DO concentration is a favor condition for niftrifier bacteria to oxidize the ammonium and improves the removal of $\mathrm{TN}$ and $\mathrm{NH}_{4}{ }^{+}-$ $\mathrm{N}$. However, decreasing aeration rate caused high dissolved organic carbon concentrations, which inhibited nitrification both in the anoxic and oxic zones and thereby increased the concentration of nitrogen in the effluent. Similar results were reported by [3], [15], [16]. Therefore, it is suggested that Johkasou system is recommended to applied continuous oxygen supply at high rate to achieve simultaneously nitrification.

\subsection{Effect of aeration rate on simultaneous nitrification and denitrification}

Adjustment of aeration rates affected the transformation of ammonia into nitrite-nitrogen and nitrate-nitrogen forms during nitrification process (Fig. 4). The amount of oxidized ammonia nitrogen via simultaneous nitrification and denitrification (SND) is calculated from the difference between total consumption of ammonia nitrogen and $\mathrm{NH}_{4}{ }^{+}-\mathrm{N}$ assimilated into heterotrophic biomass (Eq. 1) [15]. While, nitrate accumulation rate (NAR) based on the Eq. 2) $[22]$.

$$
\begin{aligned}
& \% \mathrm{SND}=\left(1-\frac{N O_{x}^{-}-N}{N H_{4}^{+}-N_{\text {oxidized }}}\right) \times 100 \\
& \% \mathrm{NAR}=\frac{N O_{2}^{-}-N}{N O_{x}^{-}-N} \times 100
\end{aligned}
$$

Where $N O_{x}^{-}-N$ is the sum of nitrite and nitrate produced at the moment when ammonia was depleted, and $\mathrm{NH}_{4}^{+}-\mathrm{N}_{\text {oxidized }}$ is the amount of ammonia nitrogen oxidized during the aerobic circumstance. NAR during nitrification stage more than $50 \%$ is indicated as nitrification via nitrite.

In the JO-A system, before adjustment of aeration rate, concentrations of ammonia were not significant differences and also $\mathrm{NO}_{\mathrm{x}}-\mathrm{N}$ formations exposed limited to a negligible amount in each process (Fig. 4a). It indicated that insufficient DO level inhibited the nitrifier bacteria to convert ammonia into $\mathrm{NO}_{2}{ }^{-} \mathrm{N}$ and $\mathrm{NO}_{3}-\mathrm{N}$ and caused the SND and NAR could not be measured as well. Contrast when the aeration was raised into $63 \%$ $\mathrm{L} / \mathrm{min}$, sufficient oxygen supply into the system could enhance nitrification with the $\mathrm{NH}_{4}{ }^{+}-\mathrm{N}$ was depleted and $\mathrm{NO}_{\mathrm{x}}{ }^{-} \mathrm{N}$ productions increased. The production of $\mathrm{NO}_{2}^{-}$ $\mathrm{N}$ detected very less because rapid conversion of $\mathrm{NO}_{2}^{-}-\mathrm{N}$ into $\mathrm{NO}_{3}^{-}-\mathrm{N}$ by Nitrobacter bacteria, which resulted percentages of NAR rose to $74.5 \%$ and $60.9 \%$, in the anoxic and oxic zones respectively. At this condition, the SND exhibited increased values in average $68.9 \%$ in the anoxic and $71.8 \%$ in the oxic. The maximum of SND value $(84.6 \%)$ was found at the beginning after increasing DO concentration in the oxic zone and the SND percentage at the last sampling was slowly declining to $64.9 \%$ during long term aeration.

Decreasing aeration rate lead to in opposition results in the JO-B system particularly after decreasing aeration rate (Fig. $\mathbf{4 b}$ ). Before adjustment, aeration rate was set upped at high rate around $59 \mathrm{~L} / \mathrm{min}$. The oxidized ammonium nitrogen was confirmed by detection of nitrite and nitrate with percentages of SND and NAR in the anoxic zone were 94\% and 93.2\%, respectively. At this condition, the nitrification process had been achieved due to appropriate oxygen supply used by nitrifier bacteria, while nitrification effect in the oxic zone not differed with in the anoxic zone.

After adjustment, DO concentration declined linearly with decreasing aeration rate to $34 \mathrm{~L} / \mathrm{min}$. This circumstance affected DO changed into very low concentration, increased ammonium concentration and depleted $\mathrm{NO}_{\mathrm{x}}^{-}-\mathrm{N}$ productions. Particular in day of 50 , the sharp dropped of nitrite and nitrate could be detected at the end of experiment with percentages of SND and NAR fell onto zero level. This circumstance resulted low accumulations of nitrite and nitrate due to limitation of oxygen for nitrification bacteria. These results indicate
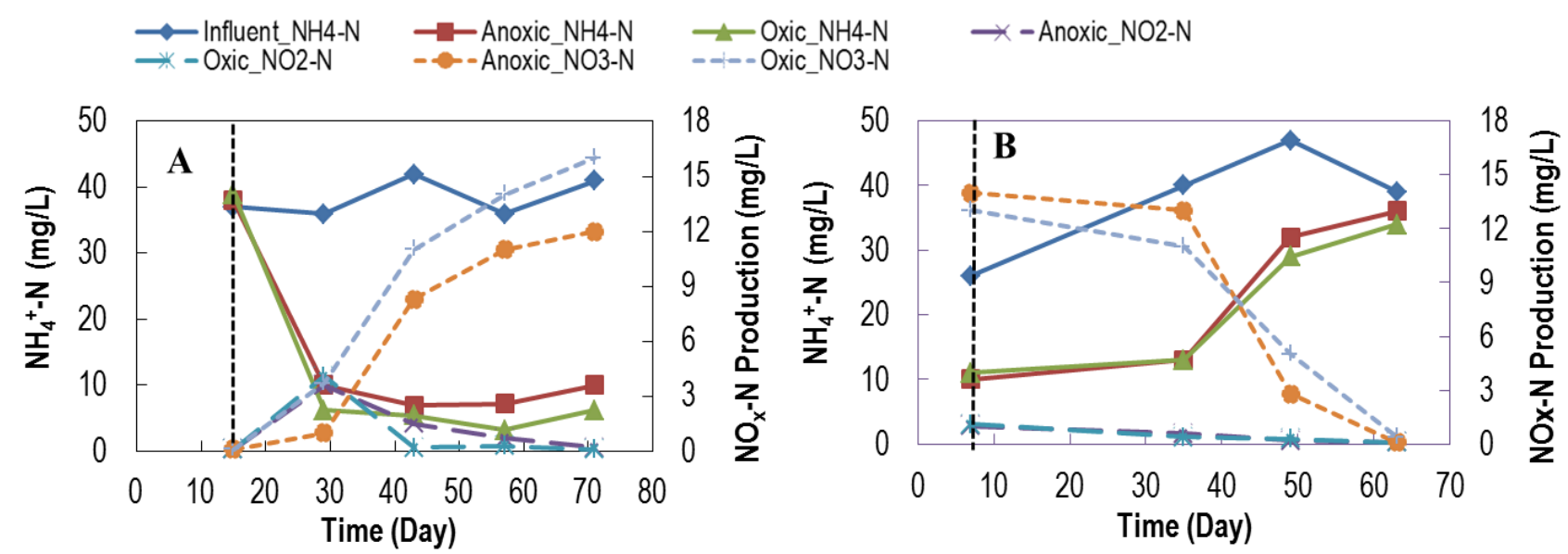

Fig. 4. Oxidized ammonia nitrogen into nitrite and nitrate affected by aeration rates in the a) JO-A and b) JO-B. 
that high DO concentration favors conditions for niftrifier bacteria to oxidize the ammonium and improve the removal percentages of $\mathrm{TN}$ and $\mathrm{NH}_{4}{ }^{+}-\mathrm{N}$. However, decreasing aeration rate caused high dissolved organic carbon concentrations, which inhibited nitrification both in the anoxic and oxic zones and thereby increased the concentration of nitrogen in the effluent. Similar results were reported by [3], [22], [23].

Limited DO concentration had no influence on the ammonia and nitrite oxidization, meanwhile the continuous supply of high DO concentration possibly inhabited oxidation of $\mathrm{NO}_{3}^{-}-\mathrm{N}$ into Nitrogen by denitrification reaction. This pointed that DO concentration plays an important role for nitrifier bacteria to oxidize the ammonia and the appropriate DO concentration or intermittent aeration supply may has a necessity to retain the oxidization, which can also save the cost of operation. The results in this study were also comparable with report by several researchers. Ruiz et al. ([14]) studied the behavior of the nitrification system during consecutive changes in DO values in high ammonia concentration. At a DO of $1.7 \mathrm{mg} / \mathrm{L}$ there was a temporal accumulation of nitrite and at DO of 1.4 and $0.7 \mathrm{mg} / \mathrm{L}$ accumulation increased with the same ammonia consumption. At a DO of $0.5 \mathrm{mg} / \mathrm{L}$, both nitrite accumulation and ammonia consumption decreased. Similar results were also obtained by Bae et al. [24] that the maximum specific oxidation of ammonia $\left(k_{a}\right)$ and nitrite $\left(k_{n}\right)$ were similar under $\mathrm{DO}=0.5 \mathrm{mg} / \mathrm{L}$ and increased as DO increased.

\section{Conclusion}

Aeration rate is an important variable in the biological wastewater treatment process and affects removals of organic matter and nitrogen. Effect of aeration rate on performance of two Johkasous was studied to know the degree oxidation of organic matter and nitrogen. High removals of BOD, DOC, $\mathrm{NH}_{4}{ }^{+}-\mathrm{N}$ and TN were achieved when the aeration was increased. The percentages of BOD and DOC removals could rich $98 \%$ and $91 \%$ respectively. And oxidization of ammonia nitrogen into nitrite and nitrate was obtained, which total mean percentages of SND and NAR were $71.8 \%$ and $60.9 \%$. Contradictory results were attained when the aeration sharply decreased and followed declining removals of organic matter and nitrogen, and increase $\mathrm{NH}_{4}{ }^{+}-\mathrm{N}$ concentration in the effluent. Therefore, it is suggested that Johkasou system is recommended to applied continuous oxygen supply at high rate to achieve simultaneously nitrification.

\section{References}

[1] T. Ichinari, A. Ohtsubo, T. Ozawa, K. Hasegawa, K. Teduka, T. Oguchi, Y. Kiso. Process Biochem. 43, 7 (2008).

[2] P. H. Chen, K. C. Leung, J. T. Wang, 26, no. 1-2, pp. 63-68 (2000)
[3] M. Zhang, P. G. Lawlor, G. Wu, B. Lynch, X. Zhan. Bioproses Biosysts Eng 34, 9, pp. 1049 1056 (2011).

[4] S. Park and W. Bae. Process Biochem. 44, 6, pp. 631-640 (2009).

[5] Y. Peng, S. Zhang, W. Zeng, S. Zheng, T. Mino, H. Satoh. Water Res 42, no. 4-5, pp. 883-892, (2008).

[6] V. M. Vadivelu, J. Keller, Z. Yuan. Water Sci. Technol.56, 7, pp. 89-97 (2007).

[7] J. Guo, Y. Peng, S. Wang, Y. Zheng, H. Huang, Z. Wang. Bioresour. Technol 100, 11, pp. 27962802 (2009).

[8] G. bing ZHU, Y. zhen PENG, S. yun WU, S. ying WANG, S. Wei XU. J. Environ. Sci 19, 9, pp. 1043-1048 (2007).

[9] G. Ruiz, D. Jeison, O. Rubilar, G. Ciudad, R. Chamy. Bioresour. Technol 97, 2, pp. 330-335, (2006).

[10] N. Kishida, J.-H. Kim, M. Chen, H. Sasaki, R. Sudo. J. Biosci. Bioeng 96, 3, pp. 285-290, (2003).

[11] Y. Z. Peng, Y. Chen, C. Y. Peng, M. Liu, S. Y. Wang, X. Q. Song, Y. W. Cui. Water Sci. Technol 50, 10 (2004).

[12] H. Yoo, K. H. Ahn, H. J. Lee, K. H. Lee, Y. J. Kwak, K. G. Song. Water Res 33, 1, pp. 145154, 1999.

[13] W. Jianlong and Y. Ning. Process Biochem 39, 10, pp. 1223-1229 (2004).

[14] W. Yang, J. Vollertsen, T. Hvitved-Jacobsen. Water Sci. Technol 48, 3, pp. 135-141 (2003).

[15] R. Naseer, S. Abualhail, L. Xiwu. Saudi J. Biol. Sci 20, 1, pp. 11-21 (2013).

[16] W. yi Dong, H. jie Wang, W. guang Li, W. chao Ying, G. Hua Gan, Y. Yang. J. Memb. Sci 344, 1-2, pp. 219-224, 2009.

[17] APHA., AWWA., WEF. Standard method for the examination of water and wastewater. 21st $E d$. New York: (APHA, 2005).

[18] R. Canziani, V. Emondi, M. Garavaglia, F. Malpei, E. Pasinetti, G. Buttiglieri. J. Memb. Sci 286, 1-2, pp. 202-212 (2006).

[19] J. Pan, H. Fei, S. Song, F. Yuan, L. Yu. Bioresour. Technol. 191, pp. 327-331 (2015).

[20] M. Kumari and B. D. Tripathi. Ecol. Eng 62, no. 3, pp. 48-53 (2014).

[21] H. Dong, Z. Qiang, T. Li, H. Jin, W. Chen. J. Environ. Sci.24, no. 4, pp. 596-601(2012).

[22] X. Yuan and D. Gao. J. Hazard. Mater 178, 1-3, pp. 1041-1045( 2010).

[23] Y. Rahimi, A. Torabian, N. Mehrdadi, B. Shahmoradi. J. Hazard. Mater 185, 2-3, pp. 852857 (2011).

[24] W. Bae, S. Baek, J. Chung, Y. Lee. Biodegradation 12, 5, pp. 359-366 (2001). 